\title{
Estudo de gênero no período pós-emancipação a partir dos Registros de Matrícula da Santa Casa de Porto Alegre (1889-1895)
}

Gender study in post- emancipation period starting from the registration records of the "Santa Casa" of Porto Alegre (1889 - 1895)

Priscilla Almaleh*

prialmaleh@hotmail.com

Resumo: Este artigo objetiva mostrar as potencialidades dos Registros de Matrícula Geral de Enfermos da Santa Casa de Misericórdia para o estudo de gênero na cidade de Porto Alegre ao fim do século XIX, mais precisamente nos anos de 1889 a 1895. Devido às novas concepções sobre o significado de gênero sabemos que os estudos sobre as populações são relacionais, ou seja, construções culturais e sociais em que o feminino e o masculino estão intimamente interligados, apesar das diversas formas de desigualdade entre os sexos. Para a pesquisa foi utilizada uma abordagem quantitativa, em que as fontes utilizadas estão ligadas à instituição assistencialista e de caridade, possibilitando o estudo da camada mais pobre da população, pois consiste em uma instituição que visava o auxílio para pessoas menos favorecidas economicamente, apesar de eventualmente encontrarmos indivíduos da classe média. Para tanto foi desenvolvida uma pesquisa com base na transcrição dos dados referentes aos livros de registros de número 6 e 7 para uma planilha de dados (Excel). Foram transcritos 12.632 dados referentes a todos os enfermos da SCMPA e após foi feita uma filtragem das diferentes etnias, classe, gênero, trabalho, estado civil, entre outras variáveis que a fonte possibilita. Apesar de ser uma fonte médica, não voltada inicialmente para tal fim, os Registros permitiram compreender diversas peculiaridades sobre a vida daqueles que procuravam a assistência médica, além de possibilitar a reconstrução da organização feminina na cidade em um período de diversas mudanças políticas e sociais como foi o período da pós-emancipação.

Palavras-chave: gênero, pós-emancipação, Santa Casa de Misericórdia de Porto Alegre

Abstract: This article aims to show the potencial of general registration records of sick people of "Santa Casa de Misericórdia" for gender study in Porto Alegre city at the end of XIX century, precisely in the years 1889 - 1895. Due to new conceptions about the meaning of gender we know that studies on populations are relational, in other words, cultural and social constructions in which the female and male are closely interconnected, despite the various forms of gender inequality. For the study was used a quantitative approach, where the sources used are linked to welfare and charitable institution, allowing the study of the poorest strata of the population, because it consists of an institution that aims to assistance to economically disadvantaged people, despite possibly find individuals of the middle class. Thus, we developed a survey based on the transcription of data on the records books 6 and 7 for a data table (Excel). Were transcribed 12.632 data relating to all the sick of the SCMPA and after it was made a filtering of different ethnic, class, gender, job, marital status, among other actions that the source provides. Despite being a medical source, not initially geared for this purpose, the records allowed us to understand many peculiarities about the lives of those who sought medical care, besides allowing the reconstruction of the women's organization in the city over a period of several political and social changes as was the post-emancipation period.

Keywords: gender, post-emancipation, Santa Casa de Misericórdia of Porto Alegre

*Mestranda em História pela Universidade do Vale do Rio dos Sinos (UNISINOS) e bolsista Capes/PROSUP. 


\section{Introdução}

Antes de começar a escrever sobre o artigo proposto é interessante esclarecer alguns pontos importantes. Primeiramente é importante considerar que apresento apenas alguns - poucos - dados da pesquisa, que por sinal está em andamento. Digo isto, para que o leitor saiba que são dados e conceitos que estão sendo analisados em constante desconstrução e reconstrução. Aqui utilizo a palavra "desconstruir" no sentindo em queque os conceitos utilizados analiticamente nas ciências humanas devem passar por um processo de desconstrução para que o próprio pesquisador não caia na armadilha de naturalizar conceitos, ou, admiti-los como universais.

Em segundo lugar, temos que atentar que todos nós enquanto humanos e pesquisadores carregamos uma bagagem, que vai de nossas crenças, pensamentos a conceitos, o que Donna Haraway (1995) chama de teoria da perspectiva. Essa teoria, em pouquíssimas palavras, acredita que a partir da afirmação de que o lugar de onde se vê e se fala - a perspectiva - determina nossa visão (e nossa fala de mundo). Portanto, para Haraway (1995) é imprescindível deixar claro para o leitor meu lugar de fala, ou, minha visão de mundo. Portanto, apesar de estar estudando o passado (uma classe pobre no fim do século XIX), carrego minhas perspectivas, meus conflitos como uma mulher acadêmica do século XXI.

Em terceiro, e último lugar, tenho que deixar esclarecido o que considero como ciência - tanto nos dias atuais, mas que pode ser confrontado e analisado com o passado - visto que no artigo serão apresentados precei- tos ditos científicos na época. De acordo com NOVAES (2015, p. 50.);

No berço das descobertas cientificas do século XVII, Descartes colocou em dúvida todo o conhecimento anteriormente elaborado, propondo um método que determinasse a unidade de ciência, destruiu as certezas para reconstrui-las inteiramente por meio de um processo metódico e único. A partir de tal postural metodológica, a busca da verdade passou a se fundamentar numa separação entre sujeito e objeto, considerando que o pólo que irradia a certeza é o sujeito que pensa e que produz o conhecimento.

Portanto, a ciência utilizou e utiliza a conduta cartesiana $^{1}$ e a partir disto vemos que a ciência foi uma criação humana e que o pólo que irradia e irradiava a ciência era formado por homens de elite e brancos, ou seja, levando em consideração apenas suas visões de mundo. Pensando por este lado, as perspectivas femininas não eram - e muito pouco, ainda são - vistas. Outro ponto que Novaes (2015) nos recorda é que as representações sociais constituem-se como uma força social resultante da própria sociedade e, portanto, da criação dos homens, que passam a ser um poder superior que se manifesta sobre esta sociedade, tanto no senso comum quanto na ciência. Em outras palavras, as pessoas se relacionam intermediadas por suas culturas, crenças e pelas representações que possuem sobre as suas realidades sociais, e, nossa cultura foi e é marcada por uma cultura patriarcal e branca que refletia na sociedade e, portanto, na ciência. Ciência como pólo de verdade, ciência que acaba ditanto regras e normas. Ciência essa que deve ser problematizada e criticada visto que acaba colocando duas oposições na sociedade: cultura e natu-

\footnotetext{
${ }^{1}$ Conforme NOVAES (2015, p. 51), “a conduta cartesiana, a ciênciatomou a natureza como objeto a ser dominado, ao mesmo tempo em que estendeu tal dominação à concepção que associa a natureza à mulher. Considerando-se que o saber científico cartesiano pressupõe uma postura de domínio e posse em relação à natureza, percebe-se que a ideologia da naturalização feminina vem apenas reforçar o subjugo da mulher no contexto da ciência."
} 
reza versus razão e emoção, justificando relações exploratórias como as "características inatas" femininas e masculinas. ${ }^{2}$

Ao pensar a diferenciação afirmada e difundida pela ciência do XIX, Rohden (2003) mostra que a reprodução feminina servia como motivo para prescrever papéis sociais diferentes para homens e mulheres. Os homens seriam mais apropriados nas atividades públicas, enquanto as mulheres seriam destinadas a vida familiar e emocional justamente pelo fato da mulher gestar, conciliando isso a capacidade intelectual e moral. Segundo Rohden, (2002, p. 115):

A ginecologia teria legitimado essa visão. Mais do que isso, é a crença na singularidade do corpo feminino como determinado à reprodução que possibilitou a formação dessa especialidade, que definiu as mulheres com um grupo particular de pacientes e um tipo distinto de espécie humana. Não é a toa que a ginecologia se desenvolveu simultaneamente às disciplinas dedicadas ao estudo cientifico da humanidade.

Com essa afirmação a autora esclarece que a medicina e os médicos em geral estavam adeptos as teorias evolucionistas e darwinistas sociais da época. Com isso, percebe-se que a natureza, a ciência e a medicina a partir da fisiologia feminina definiam lugares de homens e mulheres, classificando-os em diversas categorias racializadas e de classe. Entre as diferenças estariam o grau de civilização e a cor da pele, conectando com o ramo da antropologia para explicar essas diferenças. Essas afirmações, de acordo com a autora, acabaram saindo do campo estrito médico para um público mais geral, justificando as diferenças biológicas se legitimou as diferenças sociais.

O estudo sobre as mulheres é algo recente, data a década de 1980, e o estudo sobre as mulheres como autoras de suas próprias vidas é mais recente ainda. A historiografia tendia a representá-las nas perspectivas dos homens, geralmente personagens coadjuvantes, submissas a papéis predestinados de esposa, mãe e filha. Muitas das explicações eram destinadas a falta de fontes e informações. Após os Annales e da História Social, os grupos ditos subalternos começaram a emergir na historiografia ${ }^{\mathrm{i}}$, ocasionando uma profunda análise nas fontes.

De acordo com Joan Scott (1995) a palavra gênero começou a ser usada pelas femininas americanas, em torno da década de 1980, que queriam enfatizar o caráter fundamentalmente social das distinções baseadas no sexo, indicando uma rejeição do determinismo biológico implícito em termos como a própria palavra 'sexo'. Scott ainda enfatiza o aspecto relacional, pois acreditava-se que os homens e mulheres eram definidos em termos recíprocos e de acordo com a autora não se poderia compreender qualquer um dos 'sexos' por estudos inteiramente separados, visto que a noção desta palavra é uma construção social e não um termo fixo e imutável. Para não me alargar muito sobre este termo, é relevante para o leitor que o conceito gênero, apesar de várias definições formuladas no âmbito das ciências humanas $^{3}$, neste caso quer ressaltar e problematizar as mulheres no século XIX na cidade de Porto Alegre a partir de algumas das informações que a fonte contempla, como: questões referentes ao trabalho, classe e as

\footnotetext{
2 OLIVEIRA (2012) também revela que a maioria das pesquisas médicas realizadas a partir do ano de 1880 tendem a classificar a mulher como sexo frágil, sensível, altruísta e uma criança grande, impondo a vida familiar e doméstica como a ideal, já que as mulheres eram consideradas mais emocionais do que racionais. Essas "qualidades" femininas eram relacionadas e justificadas pelo papel reprodutivo, sendo de seu intuito biológico ser amável e cuidar dos filhos e da família.

${ }^{3}$ De acordo com Joan Scott (1995) o gênero é um elemento construído a partir das relações sociais baseadas nas diferenças percebidas entre os sexos, sendo assim uma forma de dar significado às relações de poder. A partir dessa construção das relações sociais, o gênero implica em representações simbólicas e conceitos normativos que são expressos nas doutrinas religiosas, educativas, científicas, políticas ou jurídicas e tomam a forma típica de uma oposição binária fixa, que afirma de maneira categórica e inequívoca o significado do homem e da mulher, do masculino e do feminino.
} 
cores $^{4}$ que essas mulheres são classificadas. Tenho consciência sobre uma homogeneização e que as novas críticas pós-modernas tendem a visar a diversidade, contudo, ressalto que trabalho com dados quantitativos, que me fazem perceber vários campos em relação as mulheres a partir do estudo de um conjunto de mulheres que frequentaram a Santa Casa de Misericórdia nos anos de 1889 - 1895.

A fim de esclarecimentos, utilizo o conceito de popular $^{5}$ pensando que a maioria dos enfermos frequentadores da instituição foram classificados como pobre na própria fonte devido ao caráter assistencialista e de caridade da instituição, ou seja, havia um público alvo a ser amparado e este eram os pobres materiais e espirituais $^{6}$. Contudo, conforme salienta Witter (2007), a pobreza pode estar relacionada ao contexto de não ter alguém que auxilie nos momentos de moléstia, ou seja, uma pobreza de relações e não somente de bem materiais $^{7}$. A autora lembra que o papel da família era fundamental no amparo da enfermidade, além de outros procedimentos, visto que procurar uma instituição poderia significar um ato vergonhoso já que explicitaria que o enfermo não teria a quem recorrer - fator que nos lembra que a doença era mais amenizada do que extirpada

O período escolhido é considerado cheio de mudanças sociais, pois no final do século XIX, temos o início da República, a abolição da escravatura, fatores ligados ao caráter positivista ${ }^{\text {ii }}$ da época relacionado a uma nova ordem moral e civilizatória ligada ao progresso. Entre algumas ações temos a higienista que visava à limpeza da sociedade, tanto no âmbito físico quanto no moral e era abordada pelos médicos, governantes e intelectuais do período que tendiam a ver os pobres como problema central da sociedade. Rohden (2003) esclarece que a elite, a partir das concepções cientifica se médicas tentavam ditar regras comportamentais. Seria ilusório não entender que algumas destas pessoas se apropriavam destes discursos da maneira que melhor lhe convinham, pois não conseguiam manter em suas vidas essas práticas, devido a um abismo social-econômico e moral. ${ }^{8}$

É neste contexto que muitos homens e mulheres procuraram auxílio na Santa Casa de Misericórdia ${ }^{9}$ de Porto Alegre ${ }^{10}$ para enfrentar suas enfermidades ou ter

\footnotetext{
${ }^{4}$ No decorrer do trabalho utilizo a palavra corno sentido de evidenciar a nomenclatura que a fonte dá as questões étnicas e raciais dos seus pacientes. ${ }^{5}$ Segundo Parolo (2008, p. 25) "Podemos identificar lopopular, entonces, com aquello que no formaba parte de la elite, de la cultura letrada nidel mundo de lós privilegios. Aplicado a La sociedade, se trataria, em general, del variado universo social que se caracterizaba por hallarse excluido del mundo del privilégio y delejercicio del poder, es decir, um amplio sector de lasociedad que no estaba em uma posición dominante em ló econômico, ló político y ló social. Em El habria, por ló tanto, uma enorme diversidad ocupacional, de tradiciones culturales, em riqueza e prestígio, las que permitirian establecer diferentes segmentos".

${ }^{6}$ Para maiores informações sobre o tema ver Weber (1999).

${ }^{7}$ Essa discussão é ainda muito recente neste trabalho, contudo não poderia deixar de abordar sobre o tema devido sua relevância.

${ }^{8}$ Sobre questões de discurso e pratica ver o trabalho de SANTIAGO, Silvana. Tal Conceição, Conceição de Tal: Classe, gênero e raça no cotidiano de mulheres pobres no Rio de Janeiro das primeiras décadas republicanas. Campinas, Unicamp, 2006. (dissertação de mestrado).

${ }^{9}$ As Santas Casas - instituições voltadas a caridade - apesar de existirem em algumas regiões do estado e país, não são de origem brasileira. Elas começaram na Europa, em Lisboa - Portugal em 1498, por uma associação de católicos leigos que tinha uma forte ligação com o rei e com a elite.No Brasil, cerca de trezentas nasceram durante o período de dominação portuguesa e de acordo com Cardozo (1974) foi um ambicioso e nobre empreendimento de caridade. As Santas Casas se difundiram com a colonização portuguesa, já que era comum a fundação em locais onde não havia o amparo aos menos favorecidos. Segundo Tomaschewski (2007) a iniciativa de fundar uma Santa Casa em Porto Alegre partiu de Joaquim Francisco do Livramento, vindo de Desterro (SC), que já participava da Irmandade do Senhor dos Passos. Ele estava na província recolhendo esmolas para as obras do hospital de Desterro, do qual era o principal organizador. Vendo a necessidade da criação de um hospital levou uma petição a Lisboa pedindo a autorização da construção de uma destas instituições em Porto Alegre. Em 1803, quando é organizada, atendia inicialmente os viajantes e desamparados, organizando-se com o status de Misericórdia em 1814, com o direito a receber esmolas, legados e outros rendimentos deixados para serem aplicados na construção de um hospital. O hospital, no início, era "socorrido" por médicos contratados e por "enfermeiros", geralmente pessoas com práticas na atividade da cura e da assistência. Havia, ainda, aqueles enfermos que tinham sido recolhidos, e acabavam ficando na instituição para auxiliar em serviços gerais. Os médicos apenas visitavam os pacientes algumas vezes por semana, mas a responsabilidade pelo cuidado e tratamento era dos enfermeiros, que com base nas receitas médicas deveriam cuidar do enfermo. Ao longo do século XIX, os cuidados que a SCMPA deveria prestar aos enfermos consistia em recolher os necessitados, assistindo-os com apoio material e espiritual.

${ }^{10}$ A cidade de POA - capital do Rio Grande do Sul e lócus de observação deste trabalho - estava em fase de crescimento, urbanização e industrialização. Algumas melhorias na cidade propiciaram uma melhora de vida, como a ferrovia, que foi decisiva para o aumento das exportações e para a efetivação do processo de crescimento e desenvolvimento. De acordo com Bittencourt (2013) em 1872 a população era de 43.998 e em 1890 passou para 52.421 e, em 1900 para 73.674, ou seja, a densidade demográfica de Porto Alegre era a mais alta do Estado e estava em crescente aumento. O impulso industrial da cidade ocorreu também em virtude das novas facilidades de organização empresarial que resultaram após a República. Outro fator decisivo no crescimento demográfico é a sua posição privilegiada e por ser a capital do Estado, possuindo maiores recursos financeiros e investimentos.
} 
um acalento em suas vidas. Optei por não evidenciar todos os aspectos que a fonte apresenta, mas sim os mais importantes para a construção desse artigo, como: trabalho, classe e cor, a maioria em forma de tabelas separadas por anos e por gênero.

\section{Fonte, Potencialidades e Saúde}

A História exige um método de trabalho, isto é: um conjunto de operações com instrumentos e procedimentos que demandam critérios e conhecimento. Conhecimentos prévios sobre o que se vai trabalhar (o contexto em todos seus âmbitos, a partir do problema inicial), levantamento bibliográfico (uso de vários autores que trabalharam temas semelhantes ou que auxiliem em certos conhecimentos), perguntas adequadas sobre a fonte, além de um conhecimento prévio sobre a mesma. Algumas perguntas iniciais propostas são: Quem a produziu? Para qual finalidade? Quais termos ela se utili$\mathrm{za}$ ? $^{\mathrm{iii}}$

A fonte que aqui utilizo é a Matrícula Geral dos Enfermos, documento feito pela instituição da Santa Casa de Misericórdia na cidade de Porto Alegre. Instituição, que como mencionado tinha um caráter assistencialista e de caridade, recolhendo os alienados, menores abandonados, doentes e necessitados que não tivessem onde ir, ou seja a Santa Casa de Misericórdia não tinha um caráter de "cura" como vemos hoje nos nossos hospitais, mas um lugar de repouso, de assistência e ouso dizer de acolhida ${ }^{\text {iv }}$. Voltando para fonte, é imprescindível comentar sobre sua serventia. Servia para quem? Para quem foi feita? Quem a escreveu?

Servia para os médicos em forma de acesso e informação e para a instituição como forma de controle. Informação médica, pois ali continha dados significativos sobre os pacientes, como: idade, cor, profissão, na- cionalidade e situação civil. Estas informações estão ligadas ao diagnóstico, visto que a enfermidade era demarcada pela situação do enfermo. Certas doenças eram relacionadas à cor, e por isso que essa classificação está neste contexto; a nacionalidade, devido ao clima de origem e a hereditariedade da população de certos lugares; a idade; a profissão, já que algumas ocupações poderiam tender ao contágio de certas moléstias ou a perigos de acidentes, e a situação civil, como exemplo as doenças sexualmente transmissíveis, que estavam no auge da preocupação médica ${ }^{\mathrm{v}}$. Controle, pois contava com o nome do enfermo, itens que os caracterizam fisicamente e socialmente (como a cor, nome dos pais e a idade), a situação em que saia o enfermo e a doença, que pode ser classificada como uma forma de controle, pois ali médicos e administradores - e outros - tinham consciência dos males que assolavam seu público. Respondendo a segunda pergunta, portanto, foi feita para os médicos e administradores. Por fim, provavelmente foi escrita por um escrivão.

No quadro a seguir podemos perceber a porcentagem e o número de enfermos que procuraram a Santa Casa de Misericórdia para amenizar seus males. Uso a palavra amenizar, pois a medicina estava em processo de desenvolvimento, os recursos eram baixos e os processos rudimentares, ocasionando uma melhora, mas não uma cura propriamente dita. ${ }^{11}$

\begin{tabular}{|c|c|c|c|c|c|}
\hline Ano & Homens & $\mathbf{\%}$ & Mulheres & $\mathbf{\%}$ & Total \\
\hline 1889 & 898 & $74,4 \%$ & 309 & $25,6 \%$ & 1207 \\
\hline 1890 & 1284 & $77,8 \%$ & 366 & $22,2 \%$ & 1650 \\
\hline 1891 & 1563 & $79,5 \%$ & 402 & $20,5 \%$ & 1965 \\
\hline 1892 & 1554 & $82,0 \%$ & 340 & $18,0 \%$ & 1894 \\
\hline 1893 & 1649 & $78,1 \%$ & 462 & $21,9 \%$ & 2111 \\
\hline 1894 & 1313 & $72,5 \%$ & 499 & $27,5 \%$ & 1812 \\
\hline 1895 & 1484 & $74,5 \%$ & 509 & $25,5 \%$ & 1993 \\
\hline
\end{tabular}

Quadro 1-Quantidade de enfermos classificados por gênero.

Fonte: Livro de matrícula geral de enfermos número 6 e 7 - anos $1889-$ 1895.

\footnotetext{
${ }^{11}$ Importante considerar que o período analisado é marcado pela precariedade médica, falta de homogeneização da classe, métodos doloridos utilizados pelos médicos e enfermeiros e falta de profissionais diplomados.
} 
É notável a diferença dos sexos na instituição. Por que as mulheres frequentavam menos a Santa Casa de Misericórdia? Elas tinham menos enfermidades do que os homens? Ou até, os homens sentiam mais sensibilidade a dor, por isso procuravam mais a Santa Casa? Será que as mulheres saiam menos que os homens de casa? E isto poderia fazer com que acidentes e contágios fossem menores do que o dos homens?

Provavelmente as mulheres não tinham menos enfermidades ou os homens mais sensibilidades a dor. Analisando a sociedade da época vemos que havia um ideal de mulher ligada a casa, aos serviços domésticos familiares e a manutenção da família. De acordo com Rohden(2001), esse discurso foi paulatinamente firmado na sociedade a partir da cientificidade médica e o poder que ela começou a exercer sobre as pessoas. $\mathrm{O}$ século XIX foi marcado por saberes científicos que se afirmavam e expandiam a partir da diferença, separação, oposição e hierarquia, produzindo o contexto das significativas transformações socioeconômicas que caracterizariam o século. Esta mesma autora ao analisar os escritos médicos deste período, percebe um esforço por parte desta classe em propor uma clara distinção das funções e das características socialmente aceitas dos sexos, tratando a diferença entre eles como algo natural e intrínseco, esclarecendo as razões de suas existências, redefinindo, só que agora pautado num discurso científico e biológico as bases das diferenças de papéis e gêneros como naturalmente distintos em suas características físicas, morais, sociais e psicológicas. A mulher, portanto, estaria para o lar e os afazeres domésticos como os homens para a rua e o trabalho. Contudo, autoras como Costa (2013); Perrot (2007); Santiago (2006)já evidenciaram que muitas mulheres precisavam trabalhar para gerar seu sustento e o de sua família. Portanto, as mulheres pobres trabalhavam para o sustento de si e da família, fator que as fazem tão vulneráveis aos acidentes e ao contágio quanto os homens.

Para explicar essa grande diferença alguns argumentos parecem plausíveis nesse atual momento da pesquisa. Em primeiro lugar, a Santa Casa de Misericórdia não atendia somente pessoas de Porto Alegre, mas pessoas de várias regiões ${ }^{12}$ sendo a instituição um dos principais meios médicos gratuitos o que, por ventura, dificultava o acesso fazendo com que a população procurasse outros meios de cura, mais cômodos ou próximos. Em segundo lugar, Moreira (2009) evidencia que a rua poderia ser um lugar de potencial perigo para as mulheres, fazendo assim com que elas preferissem meios de cura mais próximos de suas residências ${ }^{13}$. Ao pensarmos nos recursos de locomoção e que a população pobre estava sendo transferidas para regiões longe dos centros da cidade, periféricas, devido às novas políticas de saneamento e urbanização, vemos a dificuldade e a demora de procurar auxílio na instituição, fator que pode ser pensado como um obstáculo. ${ }^{\mathrm{vi}}$

Uma terceira via de pensamento seria a questão sobre a responsabilidade feminina. Pelo o que ou quem a mulher se responsabilizava? Claro que não podemos cair em generalizações, pois cada mulher tinha um controle sobre seu corpo a partir de suas crenças. Contudo, como já alertei no começo, difícil não cair em homogeneizações quando se trata dessa metodologia. A mulher, por gerar os filhos acabava por ficar sob a responsabili-

\footnotetext{
${ }^{12}$ A região de onde o enfermo vinha não fica evidenciado na fonte, apenas sua origem. Contudo, sabemos que pessoas de outras localidades procuravam auxílio na Santa Casa de Misericórdia, como evidencia o trabalho de Wadi (2009).

${ }^{13}$ De acordo com MOREIRA (2009) as mulheres eram raras em locais públicos, tai como bares e quando apareciam, representavam elementos potenciais de conflito acirrando a competividade entre os frequentadores. Caso estivessem desacompanhadas eram consideradas disponíveis e passíveis de serem abordadas e disputadas e, portanto, os espaços demarcavam simbolicamente seus frequentadores e mulheres honestas não circulavam, ainda mais sozinhas em público. A mobilidade das populares era estritamente controlada e determinava a forma como eram tratadas pelas autoridades em geral, jornais e mesmo entre seus pares.
} 
dade de sua criação, porém, como dito, muitas trabalhavam e mesmo assim ficavam com a responsabilidade da casa e da família. Isso quer dizer que por ter muitas obrigações à mulher não tinha "tempo" de ficar doente? Não é bem assim, sabemos que tempo e doença não são sinônimos, contudo, devido a todas essas responsabilidades ficaria difícil se internar, levando a outros tipos de tratamento, tais como curandeiros e parteiras.

De acordo com Rohden (2002) e Oliveira (2012) havia uma falta de conhecimento médico sobre o corpo feminino, e isto nos leva a quarta hipótese. No ano de 1900, ainda era comum admitir-se a incompetência científica diante dos mistérios do corpo feminino, portan- com o médico. Outra questão que podemos citar é que as mulheres procuravam auxílio com outras mulheres, pois também pensavam que o corpo feminino só poderia ser entendido por outra semelhante ou até sentirem mais confortáveis de falar sobre certos assuntos, pois o corpo feminino até hoje é visto como um tabu, como trata a autora Fabíola Rohden (2012). De acordo com Weber (1999) as parteiras, além de partos auxiliavam em questões ginecológicas e pessoais, gerando uma rede de confiança entre essas pessoas. Ao analisar a quantidade de partos observo que os números são muito baixos, o que reafirma o que os autores acima citados evidenciam, ou seja, que o desconhecimento médico juntamente com a alternativa de parteiras.

\begin{tabular}{|c|c|c|c|c|c|c|c|}
\hline Ano & $\mathbf{1 8 8 9}$ & $\mathbf{1 8 9 0}$ & $\mathbf{1 8 9 1}$ & $\mathbf{1 8 9 2}$ & $\mathbf{1 8 9 3}$ & $\mathbf{1 8 9 4}$ & $\mathbf{1 8 9 5}$ \\
\hline Gravidez & 0 & 6 & 5 & 7 & 3 & 8 & 5 \\
\hline Parto & 2 & 2 & 1 & 2 & 8 & 13 & 11 \\
\hline
\end{tabular}

Quadro 2-Números referentes a gravidez das enfermas e aos partos.

Fonte: Livro de matrícula geral de enfermos número 6 e 7 - anos 1889 - 1895.

to, nota-se que no final do século XIX, muito pouco se conhecia sobre as doenças femininas e sobre a maternidade pois a ginecologia e a obstetrícia eram campos novos nas pesquisas médicas, ocasionando um desconhecimento do corpo e das doenças femininas.

A quinta possibilidade que analiso é o pudor. Sabemos que a religião estava muito ligada à sociedade além de toda uma questão de comportamento especial para o gênero feminino. A questão moral e o não conhecimento do corpo estão ligados ao possível tratamento domiciliar, pois uma mulher ir a um médico homem ia contra a moralidade tradicional analisada anteriormente. A autoridade masculina familiar poderia ser posta em cheque, quando houvesse o contato da mulher
Os partos aumentaram gradativamente, no decorrer dos anos, possivelmente houve uma confiança médica em relação a eles, ou uma pressão social que levava as mulheres a procurarem profissionais, porém, os números são insignificantes para tal conclusão. Há, nas fontes, doenças classificadas como "gravidez" o que é amplo demais para saber sobre o que se trata. ${ }^{14}$

Essas são algumas possibilidades, porém, cada caso é um caso. Existe uma resposta única para as mulheres frequentarem menos a Santa Casa? Não. Existem possibilidades que podem ser pensadas e repensadas em formas isoladas ou em um conjunto.

\footnotetext{
${ }^{14}$ Pedro Luiz Napoleão Chernoviz observa que diversos sintomas podem vir a acompanhar a gravidez, como a fonte generaliza o termo, não fica evidente do que se trata, a não ser que é algo relacionado ao estado de grávida. O dicionário e o termo se encontram disponíveis no site: http:// dicionarios.bbm.usp.br/en/dicionario/4/gravidez.
} 


\section{O Trabalho}

Havia todo um discurso moral referente ao trabalho como regenerador da sociedade, de acordo com o pensamento da época. Podemos pensar isto como uma alternativa para expor uma ordem moral, civilizatória e de controle desses cidadãos, implantando ações que visavam o bom comportamento, a família e os bons hábitos. Porque o trabalho era visto como regenerador? Manteria as mentes ocupadas?

Herdamos esse hábito, se é que podemos chamar assim, enaltecedor do trabalho como forma de legitimidade e do crescimento pessoal, principal virtude do
A polícia, órgão coercivo, agia pela suspeição, ou seja, que todo o cidadão é suspeito de alguma coisa, porém, é sabido que alguns mais suspeitos que outros, principalmente por sua cor, gênero e situação financeira. Chalhoub (1996) ainda lembra que os pobres também ofereciam perigo de contágio - um possível motivo para haver a classificação de classe nos registros.

A civilização era sinônima de moralidade e higiene e aqueles que não as possuíam eram excluídos da sociedade e taxados como ociosos e vagabundos. Retomando as fontes, percebo que um grande número de mulheres não declara suas profissões. Porquê?

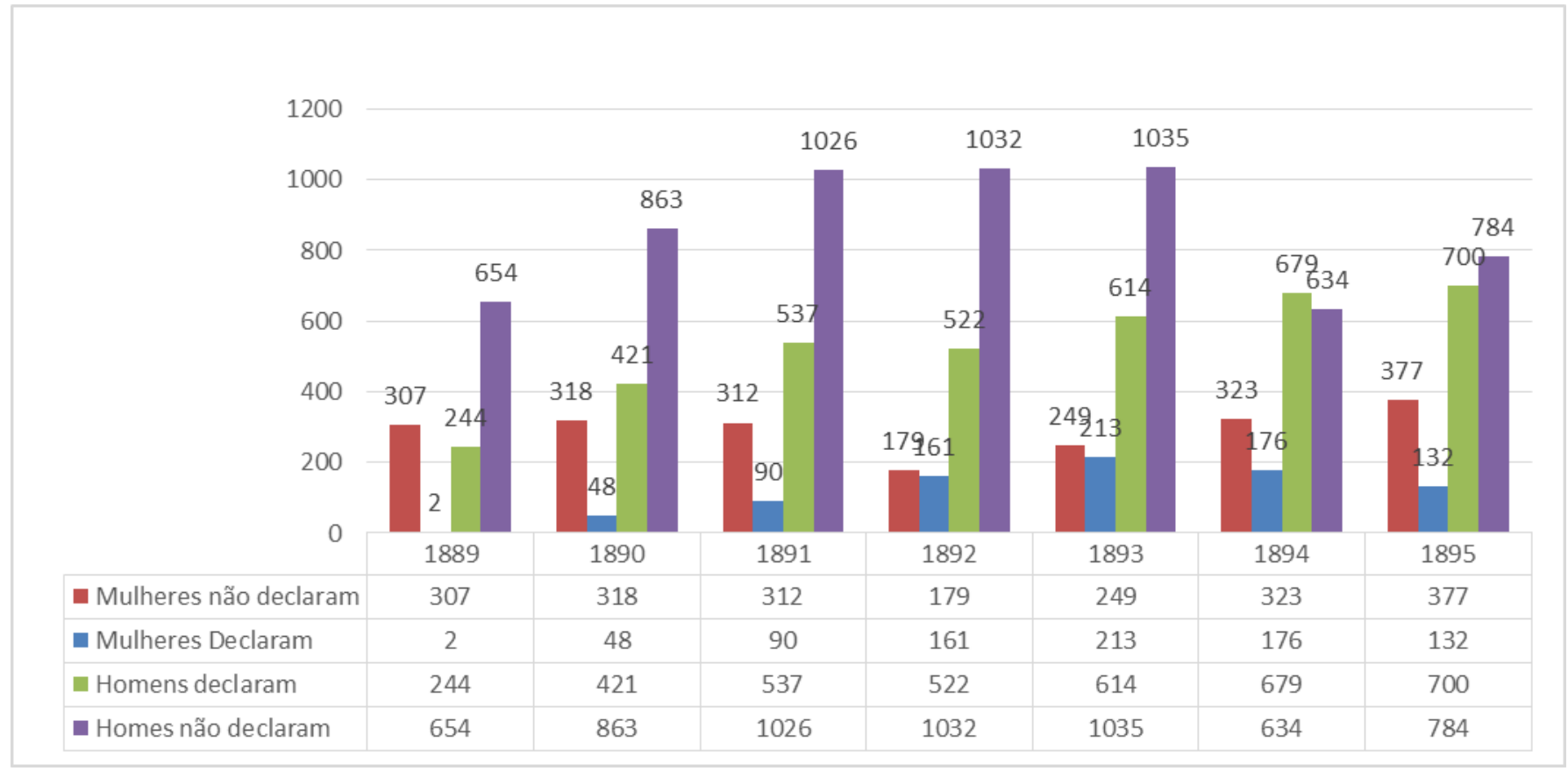

Gráfico 1-Declaração de profissões

homem, do bom cidadão que teria sua "poupança" revertida em conforto. Vejamos, se o sujeito não acumulasse ou não vivesse tentando, tornar-se-ia suspeito de ser ocioso e, portanto, provável suspeito das autoridades. De acordo com Chalhoub (1996p. 22) citando discursos da época: “[...] os pobres carregam vícios, os vícios produzem os malfeitores, os malfeitores são perigosos à sociedade; juntando os extremos da cadeia, temos a noção de que os pobres são, por definição, perigosos". O trabalho deveria extirpar esse mal.
Pensando melhor, me questionei: Será que por haver mais homens nas fontes eu considerei que eles declaravam mais? Portanto, coloquei em relação os sexos (resultando o gráfico acima) e observo que um grande número de homens e mulheres não declararam sua ocupação. Há uma oscilação em alguns anos, mas o gráfico apresenta uma relação considerável entre os gêneros.

Porque será que no ano de 1889 houve tão poucas declarações de ambos os sexos? Seria uma falha do es- 
crivão em não perguntar a profissão, visto que nos anos seguintes o número de declarações aumenta? O escrivão não perguntaria sobre o trabalho devido ao gênero? As mulheres não responderiam pensando em ser mal vistas perante a Santa Casa? Talvez, mas isto, infelizmente, a fonte não me informa e podemos pensar em apenas hipóteses. Uma pergunta considerável neste caso seria o que é trabalho para estas pessoas, podendo ser uma questão de honra para algumas já que não as torna vagabundas ou poderia soar vergonhoso a outras, pois como demonstra Rohden (2012) os desígnios naturais do papel da mulher teria como resultado uma boa preparação para assumir seu papel de mãe e esposa, com características frágeis, dóceis e sensíveis devido a sua natureza biológica, ou seja, havia um discurso médico e científico que priorizava a mulher para os afaze- res domésticos do seu lar e os homens destinados ao trabalho. ${ }^{15}$

Será que os que não declaravam não o fizeram pelas oscilações de profissões que tinham? Uma possibilidade considerável, pois estamos falando de pessoas que precisavam sobreviver em uma época que o trabalho não era regulamentado, gerando uma troca de ofícios, para algo mais rentável em um determinado momento. Isto poderia ser uma dúvida na hora de responder sua profissão, principalmente se fosse no âmbito doméstico (como foi a maioria encontrada na fonte), pois as mulheres poderiam ter uma especialização específica (como lavadeira, cozinheira, etc), ou ocupações mais gerais, que contemplam mais de uma ocupação. ${ }^{16}$

Pensando nas profissões das mulheres, temos:

\begin{tabular}{|c|c|c|c|c|c|c|c|}
\hline Profissões & $\mathbf{1 8 8 9}$ & $\mathbf{1 8 9 0}$ & $\mathbf{1 8 9 1}$ & $\mathbf{1 8 9 2}$ & $\mathbf{1 8 9 3}$ & $\mathbf{1 8 9 4}$ & $\mathbf{1 8 9 5}$ \\
\hline Agricultora & 0 & 0 & 1 & 2 & 4 & 4 & 0 \\
\hline Cartureira & 0 & 0 & 0 & 2 & 0 & 0 & 0 \\
\hline Charuteira & 0 & 0 & 0 & 0 & 0 & 1 & 0 \\
\hline Costureira & 0 & 4 & 7 & 12 & 14 & 10 & 9 \\
\hline Cozinheira & 2 & 10 & 9 & 20 & 14 & 21 & 17 \\
\hline Criada & 0 & 25 & 41 & 97 & 141 & 97 & 80 \\
\hline Criada de servir & 0 & 0 & 9 & 0 & 0 & 0 & 0 \\
\hline Engomadeira & 0 & 0 & 3 & 7 & 6 & 5 & 5 \\
\hline Irmã de Caridade & 0 & 0 & 0 & 0 & 0 & 4 & 4 \\
\hline Irmã Franciscana & 0 & 0 & 0 & 0 & 0 & 1 & 2 \\
\hline Jardineira & 0 & 0 & 2 & 0 & 0 & 0 & 0 \\
\hline Lavadeira & 0 & 3 & 9 & 16 & 15 & 14 & 14 \\
\hline Modista & 0 & 3 & 1 & 0 & 2 & 0 & 0 \\
\hline Pianista & 0 & 0 & 1 & 0 & 0 & 0 & 0 \\
\hline Operária & 0 & 0 & 0 & 0 & 5 & 1 & 0 \\
\hline Quitandeira & 0 & 0 & 0 & 2 & 3 & 1 & 0 \\
\hline Serviço doméstico & 0 & 0 & 8 & 3 & 6 & 17 & 0 \\
\hline Trabalhadora & 0 & 3 & 0 & 0 & 3 & 0 & 1 \\
\hline Total & 2 & 768 & 678 & 521 & 308 & 132 & 0 \\
\hline
\end{tabular}

Quadro 3-Profissões

Fonte: Livro de matrícula geral de enfermos número 6 e 7 - anos 1889 - 1895.

\footnotetext{
${ }^{15}$ Carla Barbosa (2015) aponta que o discurso jurídico perpassou de maneira decisiva os papeis de gênero na sociedade, afirmando certos modelos a serem exercidos por mulheres e homens, entre eles o trabalho masculino como regenerador. Scott (p. 17, 2012) ao falar sobre as diferenciações dos sexos no trabalho destaca "O homem, por sua vez, deveria ser o único provedor da família. É comum referir-se a essa nova concepção de família como inerente à "família conjugal moderna". Ao contrário do que poderíamos supor esse novo modelo de família, que transformara a mulher na "rainha do lar", manteve a mesma hierarquia com relação aos papéis masculinos e femininos, com o homem à cabeça da casa e da família e a mulher como subalterna e dependente".

${ }^{16}$ Para mais informações sobre os trabalhos domésticos femininos ver: COSTA, Ana Paula do Amaral. Criados de servir. Pelotas: Ed. Universitária UFPel, 2013.
} 
Encontramos uma grande variedade de profissões. A não declaração no âmbito feminino poderia ser pensada como um trabalho ilícito, socialmente não aceito, como no caso da prostituição. De modo algum quero "taxar" essas mulheres com este "rótulo", contudo não podemos esquecer que ao passo que a situação financeira se aperta, esta alternativa poderia se tornar viável. Trabalhos como o de Barbosa (2015), Moreira (2009), Caufield (2000) mostram que a prostituição poderia ser oscilada com outro tipo de ofício considerado lícito.

Observando a palavra trabalho de outra forma, podemos considerar que o trabalho doméstico não era considerado um trabalho formal, mas que provavelmente exercido pela maioria das mulheres. Esta é uma situação difícil de abordar, pois as feministas nos dias atuais tentam mostrar o trabalho doméstico como uma mão de obra que requer tempo, experiência, conhecimentos e certas aptidões. Hubbard (1993) observa que se não fosse o trabalho feminino doméstico não pago muitos homens não conseguiriam chegar à ascensão. Deixo aqui algo a se pensar.

Contudo, os dados da fonte me apontam a pensar que além do trabalho doméstico, as mulheres que declararam seu ofício são, na maioria, criadas na casa de terceiros, ou em ofícios ligados à esfera do lar, podendo ser fixo na casa de alguém ou não. Encontramos profissões consideradas intermediárias, como as modista e pianista, porém em pequeníssima quantidade, não excluindo a possibilidade de serem da classe popular. Encontramos duas mascates, de origem Árabe, o que me remete a imigrantes de várias etnias e procedências, que possuíam nas histórias e culturas de seus povos uma forte tradição mercantil. Penso que essas mulheres poderiam ajudar seus maridos no comércio, já que os homens árabes estão muito ligados a essa profissão. Porém uma é casada e a outra solteira, o que não significa falta de relações afetivas, visto que pode significar a presença de um matrimônio consensual. ${ }^{17}$

A improvisação da subsistência no dia a dia envolvia diversas trocas de informação, conhecimentos, favores, proteção, compadrio, concubinatos, entre outros. Essas mulheres poderiam concentrar-se em locais movimentados, onde poderiam oferecer seus serviços de lavadeiras, cozinheiras e outros no comércio em geral, marcando uma luta diária de mulheres que precisavam sustentar a família. Observo aqui um grande antagonismo entre o discurso científico médico (o qual distinguia as funções dos sexos) $)^{18}$ e a prática efetiva. $\mathrm{O}$ discurso colocava a mulher dentro do lar com designações próprias para este contexto, contudo, vemos uma prática totalmente adversa ao discurso, devido as apropriações que essas mulheres tinham do discurso relacionando com sua situação financeira e comportamental.

As criadas, maioria na fonte, poderiam sofrer com algumas vigilâncias dos patrões já que estes acostumados com a escravidão e a ideia de posse da trabalhadora criada tentaram exercer as mesmas vigilâncias. Essas mulheres também passavam a maior parte do tempo na casa das famílias que serviam, gerando contato e relação, que deveria ser harmoniosa entre a família. Há discursos liberais e práticas opressivas marcadas pelo antigo regime do cativeiro, onde o empregado não possuía nenhuma voz. De acordo com MOREIRA (2009, p. 221):

\footnotetext{
${ }^{17}$ A fonte ainda aborda a condição civil de seus pacientes, contudo, nesse trabalho não utilizarei essa abordagem devido a falta de espaço.

${ }^{18}$ A mulher era reservada a esfera do lar e aos afazeres domésticos como ações naturais, ideais e morais para a mulher honrada socialmente e virtuosa moralmente. Vemos um discurso pautado em uma esfera binária de oposições: cultura e natureza versus razão e emoção o que acaba por justificar relações exploratórias por "características inatas e predeterminadas" femininas e masculinas. Emoção e natureza reservada às mulheres e razão e cultura para os homens, com isto o lar está socialmente aceito para as mulheres como a rua para os homens.
} 
Parte importante dos ganhos obtidos pelas criadas devia ser garantida pela moradia e alimentação junto à casa dos patrões. Mesmo assim, parte dessas populares preferiam habitar por conta própria em quartos de cortiço ou casebres, divididos com eventuais amásios (como soldados ou marítimos, por exemplo) ou companheiras de casa. Nestas casas, elas lucravam não só em termos afetivos, como os ganhos com criadas podiam ser acrescidos de eventuais serviços para fora, como lavagens de roupas, costuras e mesmo prostituição.

A formulação de regulamentos específicos para controlar a vida e o trabalho dos criados, a hierarquia entre trabalhadores domésticos que serviam na rua e em casa $^{\text {vii }}$ servia para manter a ordem social, frear a vagabundagem e prevenir os patrões dos possíveis "contágios" dos criados.

\section{Cor}

Um dos dados mais relevantes desta fonte é o fato dela possuir a cor dos enfermos. Historiadoras como Hebe Mattos e Ana Maria Rios (2004, p.176), ao estudar problemas das fontes no período da pós abolição declaram:

Esta é uma dificuldade geral nas pesquisas sobre a experiência histórica pósemancipação nas Américas. No Brasil, entretanto, é especialmente acentuada, não apenas pela inexistência de práticas legais, baseadas em distinção de cor e raça ou pela presença demograficamente expressiva, e mesmo majoritária, de negros e mestiços livres, antes da abolição, mas pelo desaparecimento que se fez notar desde meados do século XIX, de se discriminar a cor dos homens livres nos registros históricos disponiveis. Processos civeis e criminais, registros paroquiais de batismos, casamentos e óbitos, na maioria dos casos não faz menção da cor [...].

Antes de pensarmos na cor destes indivíduos, devemos levar em consideração o que significava a "noção de cor", herdada do período colonial. Mattos (2013) considera que a cor não designava a pigmenta- ção da pele em si, mas definia lugares sociais. A autora dá o exemplo das cores "preto" e "negro", que quando usadas em pessoas livres significava proximidade ao cativeiro. Já a cor "parda" indica alguém que já se distanciou dessa condição. A partir desta análise podemos considerar que a cor estava ligada a liberdade e a posição social do indivíduo.

Apesar da sociedade ter sido hierarquizada de maneira desigual, tentou-se não evidenciar essa desigualdade na lei e nas fontes, a população, embranquecendo os registros ou invisibilizando as cores. Contudo, há autores como Rosa (2014) em sua tese de doutorado "Além da invisibilidade: história social do racismo em Porto Alegre durante o pós-abolição (1884 - 1918)"que apontam que mesmo a menção de cor não estar explícita, há outras formas de simbolismos que adjetivam as pessoas nas fontes, mostrando, portanto, indícios de sua cor.

Possivelmente a aparição das cores aqui apresentadas é devido ao diagnóstico médico, pois a raça e a cor do indivíduo estavam ligadas ao surgimento e a probabilidade de algumas doenças. O final do século XIX, mais precisamente na década de 1870 , de acordo com Schwarcz (1993), representa o momento de entrada de um novo ideário positivista-evolucionista em que os modelos raciais cumprem um papel fundamental. Este período também compreende um momento de fortalecimento e amadurecimento de alguns centros etnográficos e podemos citar as faculdades, e as suas influencias nos hospitais. O termo raça, além de ser vista por sua definição biológica, era vista também no contexto social, ou seja, as teorias raciais se apresentavam enquanto modelo teórico viável na justificação do jogo de interesses que se montava, uma racialização social. ${ }^{\text {viii }}$ 


\begin{tabular}{|c|c|c|c|c|c|c|c|}
\hline Cores & $\mathbf{1 8 8 9}$ & $\mathbf{1 8 9 0}$ & $\mathbf{1 8 9 1}$ & $\mathbf{1 8 9 2}$ & $\mathbf{1 8 9 3}$ & $\mathbf{1 8 9 4}$ & $\mathbf{1 8 9 5}$ \\
\hline Branca & 110 & 122 & 183 & 131 & 213 & 224 & 191 \\
\hline Cabra & 1 & 0 & 0 & 0 & 0 & 0 & 0 \\
\hline China & 8 & 5 & 1 & 0 & 0 & 0 & 0 \\
\hline Índia/Indiática & 3 & 12 & 17 & 17 & 46 & 82 & 69 \\
\hline Morena & 11 & 18 & 5 & 9 & 16 & 17 & 4 \\
\hline Parda & 71 & 90 & 58 & 67 & 83 & 67 & 89 \\
\hline Preta & 105 & 117 & 137 & 115 & 103 & 109 & 156 \\
\hline Nãoconsta & 0 & 2 & 1 & 1 & 1 & 0 & 0 \\
\hline Total & 309 & 366 & 402 & 340 & 462 & 499 & 509 \\
\hline
\end{tabular}

Quadro 4-As cores das enfermas da SCMPA.

Fonte: Livro de matrícula geral de enfermos número 6 e 7 - anos 1889 - 1895.

A primeira coisa que chama a atenção é a existência, no pós-1889, de seis formas de classificação de cor para os não brancos. Como observado acima, as cores, além da epiderme, podem significar estigmas sociais. Por exemplo, na categoria "china" são incluídas preferencialmente pessoas oriundas dos países como Paraguai, Uruguai e Argentina, significando, talvez, alguma característica das pessoas destes lugares, como traços indígenas, além de pessoas do próprio estado, descendentes de povos nativos. A denominação "china", também pode ser dirigida a mulheres que aderem à prostituição como ofício, ou são vistas como meretrizes por seus comportamentos sexuais e afetivos independentes. Não posso afirmar se essas mulheres eram prostitutas ou não, pois a fonte não me permite, mas vale pensar em algumas possibilidades que podemos atribuir. ${ }^{19}$

Outro dado importante para a pesquisa é que se somarmos os não-brancos na tabela. O que levo a concluir que as enfermas da Santa Casa de Misericórdia em sua maioria eram mestiças ou negras, apesar da quantidade de brancas encontradas serem significativas.
As outras nomenclaturas, como, "índia", "indiática", indicam enfermas de cores e traços caracterizadas como indígenas. Já as nomeadas "cabra", "morena" e "parda" são de difíceis significações e interpretações, visto que dependia do olhar do funcionário. Provavelmente remetem a cores e traços mestiços.

No caso específico desta fonte, há uma probabilidade de que os dados ali constantes eram preenchidos pelos próprios funcionários da instituição, baseados no conhecimento que tinham dos doentes que ali chegavam, da sua percepção visual. Um dos motivos para chegar a esta conclusão é o encontro, especificadamente no livro de matrículas número 7 , de um paciente sem maiores informações a seu respeito. Este paciente é retratado como um homem mudo, e não há informações sobre seus pais, local de origem, estado civil ou se possuí ou não emprego. Porém, sua cor é representada como preta e sua idade de 50 anos. Ou seja, concluímos que a idade e a sua cor foram atribuídas pela aparência por algum funcionário que o atendeu, mas resta-nos saber se isso ocorria em todos os casos - principalmente a cor - ou em alguns específicos, como este homem que não podia se comunicar, e consequentemente, se declarar sua cor.

\footnotetext{
${ }^{19}$ Sobre a prostituição ver a tese de doutorado de PEREIRA, Cristiana Schettini. Que tenhas teu corpo:Uma história social da prostituição no Rio de Janeiro das primeiras décadas republicanas. Campinas - Unicamp,2002. (tese de doutorado).
} 


\section{Conclusão}

Há diversas possibilidades e cruzamentos ao trabalhar apenas os Registros de Matrícula Geral dos Enfermos da Santa Casa de Misericórdia. Observo também a importância de trabalhar questões ligadas ao gênero na história social, pois há uma gama de histórias serem recontadas, encontradas e pesquisadas que podem vir a dar novos rumos aos estudos de gênero e história das mulheres, que por muito tempo ficaram esquecidas pela historiografia.
Além de um lugar de assistência a SCM era um lugar de interação, de encontro e principalmente, de múltiplas culturas que acabavam por trocar experiências e contatos. Várias pessoas de diversas etnias se multiplicavam em um espaço onde a enfermidade era o foco central, mas que amizades, encontros, reencontros, desencontros, paixões, ódios e outros sentimentos poderiam ser explorados, afinal eram seres humanos e o que há de mais complexo no mundo são os sentimentos, e estes, infelizmente não há como recontar.

${ }^{\text {i }}$ Para saber mais sobre a emergência da História Social ver: MATTOS, Hebe. História Social. In: CARDOSO, Ciro Flamiron; VAINFAS, Ronaldo. Domínios da História: ensaios de teologia e metodologia. Rio de Janeiro: Campus, 1977. p.281-294.

${ }^{i i}$ Para mais informações sobre o positivismo: PINTO, Celi Regina J. Positivismo: Um projeto político alternativo (RS: 1889 - 1930). Porto Alegre: L\&PM, 1986.

${ }^{\text {iii }}$ Para maiores informações sobre métodos na pesquisa histórica indico uma fácil leitura: SAMARA, Eni de Mesquita; TUPY, Ismênia S. Silveira T. Tupy. História \& Documento e metodologia de pesquisa. Belo Horizonte: Autentica, 2007.

${ }^{\text {iv }}$ Veja mais em: WITTER, Nikelen Acosta. Males e epidemias: sofredores, governantes e curadores no sul do Brasil (Rio Grande do Sul, século XIX). Rio de Janeiro, PPGH/UFF, 2007. (Tese de Doutorado).

${ }^{v}$ Veja mais em: OLIVEIRA, Daniel. Morte e Vida Feminina: Mulheres Pobres, Condições de Saúde e Medicina da Mulher na Santa Casa de Misericórdia de Porto Alegre (1880-1900). POA, UFRGS, 2012 (Dissertação de Mestrado).

${ }^{\text {vi }}$ Para isto aconselho o livro de BITTENCOURT. Dóris Maria Machado de. Casa, alcova e mulher. Santa Cruz do Sul: EDUNISC, 2013. Sobre classes perigosas ver: CHALHOUB, Sidney. Cidade febril: cortiços e epidemias na Corte imperial. São Paulo - SP: Companhia das Letras, 1996.

${ }^{\text {vii }}$ Para saber mais sobre as hierarquias: GRAHAM, Sandra Lauderdale. Proteção e Obediência. Criadas e seus patrões no Rio de Janeiro (1860 - 1910). São Paulo: Companhia das Letras, 1992.

viii Indico a leitura do texto de GUIMARÃES, Antonio Sérgio Alfredo. Raça, cor e outros conceitos analíticos. In: PINHO, Osmundo; SANSONE, Lívio Raça: novas perspectivas antropológicas. Salvador: EDUFBA, 2008. 


\section{Referências bibliográficas:}

BARBOSA, Carla Adriana da Silva. 'José casou com Maroca e Antônio casou-se com Fina." Relações de gênero e violência e afetivo-sexual no Sul do Brasil (RS, 1889-1930). Porto Alegre, Tese (Doutorado). Universidade Federal do Rio Grande do Sul, 2015.

BITTENCOURT. Dóris Maria Machado de. Casa, alcova e mulher. Santa Cruz do Sul: EDUNISC, 2013.

CAUFIELD, Sueann. Em defesa da honra. Campinas: Editora Unicamp, 2005.

CHALHOUB, Sidney. Cidade febril: cortiços e epidemias na Corte imperial. São Paulo - SP: Companhia das Letras, 1996.

COSTA, Ana Paula do Amaral. Criados de servir. Pelotas: Ed. Universitária UFPel, 2013.

GRAHAM, Sandra Lauderdale. Proteção e Obediência. Criadas e seus patrões no Rio de Janeiro (1860 - 1910). São Paulo: Companhia das Letras, 1992.

GUIMARÃES, Antonio Sérgio Alfredo. Raça, cor e outros conceitos analíticos. In: PINHO, Osmundo; SANSONE, Lívio. Raça: novas perspectivas antropológicas. Salvador: EDUFBA, 2008.

HUBBARD, Ruth. Algumas idéias sobre a masculinidade das ciências naturais. In: GERGEN, Mary Mc Canney. O pensamento feminista e a estrutura do conhecimento. Rio de Janeiro: Rosa dos tempos: EDUNB, 1993.

HARAWAY, Donna. Saberes Localizados. Cadernos Pagu, v. 5, p. 11-41, 1995.

MATTOS, Hebe. História Social. In: CARDOSO, Ciro Flamiron; VAINFAS, Ronaldo. Domínios da História: ensaios de teologia e metodologia. Rio de Janeiro: Campus, 1977. p. 281-294.

MOHANTY, ChandraTalpade. Bajo losojos de Occidente: academia feminista y discursos coloniales. In: Descolonizando El feminismo. NAVAZ, Liliana Suáreez, CASTILO, Rosalva Aída Hernandez. Valencia, España, Instituto de La mujer, Ediciones Cátedra, Universidad de Valencia, 2008.

MOREIRA, Paulo Roberto Staudt. Entre o deboche e a rapina: os cenários sociais da criminalidade popular em Porto Alegre. Porto Alegre: Armazém digital, 2009.

MATTOS, Hebe. Das cores do silêncio: os significados da liberdade no sudeste escravista - Brasil século XIX. São Paulo: Unicamp, 2013.

NOVAES, Elizabete Davis. Entre o público e o privado: o papel da mulher nos movimentos sociais e a conquista de direitos no decorrer da história. História e Cultura, Franca, v. 4, n. 3, dez. 2015, p. 50 -66.

OLIVEIRA, Daniel. Morte e Vida Feminina: Mulheres Pobres, Condições de Saúde e Medicina da Mulher na Santa Casa de Misericórdia de Porto Alegre (1880-1900). POA, Dissertação (Mestrado), UFRGS, 2012.

ROSA, Marcus Vinicius de Freitas. Além da invisibilidade: história social do racismo em Porto Alegre durante o pós-abolição (1884 - 1918). Campinas, Tese (Doutorado). Unicamp, 2014.

SAMARA, Eni de Mesquita; TUPY, Ismênia S. Silveira T. Tupy. História \& Documento e metodologia de pesquisa. Belo Horizonte: Autentica, 2007.

SCOTT, Joan. Gênero: uma categoria útil de análise histórica. Educação e realidade. jul./dez., 1995, p. 71 - 90.

PAROLO, María Paula. Introdución. In: PAROLO, María Paula. Ni súplicas, niruegos: Lasestratefias de subsistência de lós sectores populares em Tucumán ela primera mitad del siglo XIX. Rosario, Argentina: Prohistoria, 2008 .

PEREIRA, Cristiana Schettini. Que tenhas teu corpo: Uma história social da prostituição no Rio de Janeiro das 
primeiras décadas republicanas. Campinas, Tese (Doutorado). Unicamp, 2002.

PERROT, Michelle. Minha história das mulheres. São Paulo: Contexto, 2007.

PINTO, Celi Regina J. Positivismo: Um projeto político alternativo (RS: 1889 - 1930). Porto Alegre: L\&PM, 1986.

RIOS, Ana Maria; MATTOS, Hebe Maria. O pós abolição como problema histórico: balanços e perspectivas. Topoi, v. 5 , n. 8, jan./jun., 2004, p.170-198.

ROHDEN, Fabíola. A construção da diferença sexual na medicina. Cadernos de saúde pública, Rio de Janeiro. 19 (sup. 2): S201 - S212, 2003.

ROHDEN, Fabíola. Ginecologia, gênero e sexualidade na ciência do século XIX. Revista Horizontes Antropológicos, n. 17, jun. 2002, p. 101-125.

SANTIAGO, Silvana. Tal Conceição, Conceição de Tal: Classe, gênero e raça no cotidiano de mulheres pobres no Rio de Janeiro das primeiras décadas republicanas. Campinas, Dissertação (Mestrado), Unicamp, 2006.

SCHWARCZ, Lilia Moritz. O espetáculo das raças: cientistas, instituições e questão racial no Brasil 1870 - 1930. São Paulo: Companhia das Letras, 1993.

WADI, Yonissa Marmitt. A História de Pierina: Subjetividade, crime e loucura. Uberlândia: EDUFU, 2009.

WEBER, Beatriz Teixeira. As artes de curar: medicina, religião magia e positivismo na República Rio-Grandense - 1889-1928. Santa Maria: UFSM, 1999.

WITTER, Nikelen Acosta. Males e epidemias: sofredores, governantes e curadores no sul do Brasil (Rio Grande do Sul, século XIX). Rio de Janeiro, Tese (Doutorado). PPGH/UFF, 2007.

Submissão: $22 / 05 / 2016$

Aceite: 25/10/2016 